\title{
Operações urbanas consorciadas com Cepac: uma face da constituição do complexo imobiliário-financeiro no Brasil?
}

\author{
Urban partnership operations with Cepac: \\ a part of the constitution of the real \\ estate-financial complex in Brazil?
}

Laisa Eleonora Maróstica Stroher

\section{Resumo}

Este trabalho propicia uma visão panorâmica crítica sobre a literatura acerca da implementação das Operações Urbanas Consorciadas (OUCs) com Certificado de Potencial Adicional Construtivo (Cepac) no Brasil, com base em um enfoque teórico inspirado nos debates sobre financeirização espacial, de forma articulada à abordagem dos regimes espaciais estatais (da Escola de Regulação anglo-saxã). A metodologia baseou-se em uma seleção de artigos sobre experiências de OUCs, os quais foram analisados a partir de questionamentos centrais às abordagens teóricas elencadas, a saber: "quais as principais articulações entre os agentes do mercado financeiro, imobiliário e o Estado e quais suas estratégias (materiais e discursivas)?"; "De que forma as disputas em torno das OUCs têm contribuído para moldar o Estado?"; e "Quais as principais contradições socioespaciais promovidas?".

Palavras-chave: operação urbana consorciada; Cepac; financeirização urbana; reescalonamento; grandes projetos urbanos.

\begin{abstract}
This article provides a critical overview of the literature on the implementation of Urban Partnership Operations (UPOs) with Cepac (additional building right certificate) in Brazil, based on a theoretical approach inspired by debates on spatial financialization, in articulation with the state spatial regimes approach (as discussed by the Anglo-Saxon Regulation School). The methodology was based on a search and selection of papers that address UPO experiences. The papers were analyzed from central issues related to the theoretical debates discussed, namely: What are the main articulations among financial market agents, real estate market agents and the State? What are their strategies (material and discursive)? How have struggles over UPOs contributed to shaping the State? What are the main socio-spatial contradictions that have been promoted?
\end{abstract}

Keywords: urban partnership operations; Cepac; urban financialization; rescaling; large urban projects. 


\section{Introdução}

Este trabalho ${ }^{1}$ visa propiciar uma visão panorâmica sobre a literatura acerca da implementação das Operações Urbanas Consorciadas (OUCs) no Brasil, com base em um enfoque teórico inspirado nos debates sobre financeirização espacial de forma articulada à abordagem dos regimes espaciais do Estado, da Escola de Regulação anglo-saxã. A partir dessa ótica, pretende-se discutir os nexos entre 0 processo de financeirização global e as disputas locais que envolvem as OUCs. Busca-se, ainda, contextualizar as OUCs como parte da dinâmica de reestruturação territorial-escalar pós-crise do Estado Nacional Desenvolvimentista ${ }^{2}$ no País.

A metodologia de pesquisa baseou-se, em uma primeira etapa, em busca e seleção de artigos que abordassem experiências de implementação de OUCs. Em seguida, tais artigos foram analisados a partir de questionamentos centrais aos debates teóricos elencados, a saber:

- quais as principais articulações entre os agentes do mercado financeiro, imobiliário e o Estado; e quais suas estratégias (materiais e discursivas)?

- De que forma as disputas em torno das OUCs têm contribuído para moldar o Estado?

- Quais as principais contradições socioespaciais promovidas?

Interessa, ainda, analisar quais as lentes teóricas utilizadas nos trabalhos, a fim de refletir sobre possíveis complementaridades ou divergências entre as teorias que suportam as análises sobre as OUCs, bem como verificar as possibilidades de diálogos com o quadro teórico aqui discutido. Pretende-se, dessa forma, contribuir para uma aproximação entre a práxis e os debates teóricos no campo dos estudos urbanos, já que, como argumenta Law-Yone (2007), a produção teórica nesse campo vem paulatinamente se distanciando dos contextos práticos, materiais e sociais do planejamento urbano.

Como fonte de pesquisa, foram estabelecidos os artigos das revistas indexadas pela Coordenação de Aperfeiçoamento de Pessoal de Nível Superior (Capes). Em seu portal, foram encontrados dezoito artigos que discutem experiências de $\mathrm{OUCs}{ }^{3}$ dos quais foram escoIhidos apenas oito para serem problematizados, uma vez que foram excluídos os artigos que tratam de OUCs que não chegaram a se efetivar ou que não relacionavam discussões teóricas aos estudos de caso.

$\mathrm{O}$ trabalho é dividido em três partes. $\mathrm{Na}$ primeira são apresentadas as lentes teóricas através das quais se pretende discutir os artigos, sem pretensões de esgotar o tema. Na segunda é problematizado o resultado da análise dos trabalhos, que abordam quatro OUCs em curso: Água Branca (um artigo), Água Espraiada e Faria Lima (cinco artigos), ambas em São Paulo; e Porto Maravilha (dois artigos), no Rio de Janeiro. Nas conclusões, são apresentadas as principais constatações a respeito dos questionamentos que motivaram a pesquisa, além de considerações sobre lacunas na literatura que contribuem para compor uma agenda futura de pesquisa. 
Reescalonamento \& financeirização espacial

Essa abordagem se baseia na teoria dos regimes espaciais, formulada por Brenner (2004). Trata-se de teoria realizada a partir de uma articulação entre o materialismo científico geográfico - de Lefebvre, Harvey, entre outros - e a teoria do Estado Estratégico Relacional - de Bob Jessop. Entende-se, a partir dessa visão, que o Estado e a sua espacialidade (a forma como se organiza e intervém no espaço, nas diversas escalas) não são estáticos, ambos se alteram em função das mudanças no regime de acumulação capitalista, bem como através da luta dos agentes pelo Estado, buscando preenchê-lo de acordo com seus interesses. Essa interação é determinante para compreender a seletividade do Estado em relação aos espaços (territórios de intervenção, escalas de governança, etc.) e aos grupos sociais priorizados em determinado momento histórico.

A partir desse entendimento, diversos autores têm demonstrado como a espacialidade do Estado tem se moldado a partir da crise do Estado de Bem-Estar, com especial atenção a Europa Ocidental e Estados Unidos. Brenner (2004) tem teorizado sobre a transição de um regime espacial keynesiano - baseado (predominantemente) em projetos e estratégias redistributivos coordenados pelo Estado Nação - para um regime espacial reescalonado e competitivo. Em linhas gerais, evidencia-se a emergência de um regime com enfoque na competitividade urbano-regional, bem como na proeminência do papel de outras escalas (como as supranacionais e subnacionais). 0 autor entende que esse regime tem aumentado as instabilidades e as disparidades territoriais, através da difusão de estratégias empresariais de gestão urbana.

Um dos temas-chave relacionados à desestruturação do regime keynesiano refere-se à importância que têm assumido os grandes projetos de desenvolvimento urbano (GPUs) fomentados através de Parcerias Público-Privadas (PPPs), como forma de promover a competição entre as cidades para atrair 0 capital financeiro internacional excedente (Brenner, 2004; Harvey, 1989; Swyngedouw, Moulaert e Rodriguez, 2002). Essa forma de intervenção tem sido amparada pelo paradigma do planejamento estratégico. Antigas áreas industriais, áreas portuárias e terrenos vagos foram ocupados por megaempreendimentos imobiliários, que passaram a representar as novas centralidades urbanas: como o London Docklands, em Londres; o Battery Park City, em Nova York e La Défense, em Paris (Nobre, 2009). Os antigos usos foram substituídos por outros mais rentáveis, priorizados pela reestruturação econômica, como serviços financeiros, de comunicação, turismo e entretenimento.

Outra expressão importante do reescalonamento do Estado refere-se à chamada financeirização do espaço. Embora esse tema não seja usualmente tratado nos trabalhos que discutem a teoria do reescalonamento estatal nem na literatura sobre os GPUs, entende-se que ele seja central para entender as transformações na atuação do Estado, bem como os conflitos que circundam a implementação dos processos de renovação urbana.

0 debate sobre a financeirização destaca a centralidade da terra e do ambiente construído para o salto de capital fictício nas últimas décadas, por meio da criação de uma enorme 
variedade de instrumentos que ligam o fundiário e o imobiliário ao mercado de capitais, como: a securitização das hipotecas habitacionais, das rendas provenientes de aluguéis, dos impostos ligados ao imobiliário e fundiário (Aalbers, 2008; Weber, 2010; Fix, 2011). Esses ativos financeiros têm sido alguns dos principais alvos da nuvem de capital excedente da Ásia, Europa e Estados Unidos, especialmente a partir dos anos 1990.

Dessa forma, uma gama maior e mais diversificada de atores (agentes do mercado financeiro, investidores no mercado de capitais, etc.), em diversas partes do mundo, passa a participar dos jogos especulativos imobiliários locais, alterando a estrutura do conflito sobre a produção do espaço. Em termos de reescalonamento, é possível afirmar que, com a financeirização, as disputas em torno do espaço são cada vez menos definidas pelos processos que ocorrem nos contornos locais e nacionais estritos, tratando-se cada vez mais de uma luta glocalizada. Evidentemente, que a trajetória de financeirização é muito diferenciada de acordo com contexto histórico e geográfico, especialmente se compararmos 0 Sul e o Norte globais.

Além de um processo de imbricação maior entre as múltiplas escalas, é possível observar uma articulação mais estreita entre os agentes que atuam no Estado, no setor financeiro e no imobiliário. A fim de chamar atenção à centralidade dessa coalizão, Aalbers (2008) cunhou o termo "complexo imobiliário-financeiro". Um dos impactos dessa conexão na política urbana e habitacional tem sido possibilitar uma ótica cada vez mais forte da terra e da moradia enquanto meros ativos financeiros, em contraposição a uma visão enquanto bens coletivos (Aalbers, 2008; Rolnik, 2015), o que implica direcionamentos bastante distintos da política urbana.

Ao analisar os impactos sobre a política habitacional em vários países nas últimas décadas, Rolnik (2015) destaca dois movimentos simultâneos: um enfoque em políticas que visam ao acesso à moradia pela via da propriedade privada (condição essencial para que a casa possa se tornar um ativo financeiro mais líquido) - o que implicou, por exemplo, processos de privatização de antigos parques públicos habitacionais de aluguel na Europa - e uma posterior reestruturação regulatória do financiamento imobiliário, para possibilitar a promoção dos títulos financeiros lastreados em imóveis.

No que tange ao planejamento urbano, um dos impactos discutidos é a subordinação dos projetos de renovação urbana aos interesses do complexo imobiliário-financeiro (Weber, 2010; Guironnet e Halbert, 2015; Savini e Aalbers, 2015; Kaika e Rugierro, 2016). Essas literaturas debatem os efeitos da articulação desses projetos com arranjos financeiros vinculados ao mercado de capitais (por meio de composições diversas, envolvendo securitização de impostos das áreas de renovação, articulações com fundos de investimento imobiliários e outros). Uma das consequências relaciona-se à penetração da lógica de valorização rápida (própria dos investidores no mercado de capitais), o que influencia no direcionamento do projeto para privilegiar usos com maior potencial de alavancar a valorização imobiliária (que lastreia os ativos financeiros), em detrimento de outros usos mais conectados às necessidades efetivas da população das áreas de intervenção. ${ }^{4}$ 


\section{Reescalonamento do Estado Nacional Desenvolvimentista e financeirização urbana no Brasil}

Em relação ao contexto brasileiro, essas transformações não ocorrem nos mesmos termos, visto que o País nunca viveu um regime de acumulação semelhante ao fordista keynesiano. Em distinção ao Estado de Bem-Estar Social, vigorou no Brasil, entre os anos 1930 e início dos anos 1980, um modelo específico de Estado Nacional Desenvolvimentista, que associou elevadas taxas de crescimento econômico a um processo intenso de polarização socioespacial. Portanto, os impactos do urbanismo neoliberal e da financeirização no Brasil podem ser entendidos mais como um reforço da lógica seletiva de intervenção territorial do Estado, do que, de fato, como uma ruptura com o padrão que vigorou nos anos guiados pelas políticas desenvolvimentistas (como discutido em Klink, 2014 e Stroher, 2017).

Vários autores que têm estudado aspectos da financeirização espacial brasileira (Fix, 2011; Klink e Denaldi, 2014; Royer, 2014) identificam a emergência desse fenômeno com a desestruturação do Nacional Desenvolvimentismo, especialmente a partir dos anos 1990. 0 caminho para impulsionar as formas privadas de financiamento habitacional no Brasil foi aberto após os ajustes econômicos nos anos 1990, com maior força especialmente após plano de estabilização econômica do governo Fernando Henrique. A diminuição e a estabilização da inflação, alcançadas pelo Plano Real, reduziram os riscos investidores e abriram perspectivas para impulsionar os mercados de crédito privado de longo prazo, ${ }^{5}$ o que contribuiu para a criação do Sistema Financeiro Imobiliário (SFI), em 1997.

O SFI propiciou um quadro institucional para a captação de recursos no mercado de capitais para financiar o setor imobiliário, nos moldes dos Estados Unidos e da Europa, inspirado no paradigma da nova economia institucional (Royer, 2014). Apesar de a justificativa do SFI se estruturar na ideia de maior eficiência do setor privado e na substituição do Sistema Financeiro Habitacional (SFH), mediado pelo Estado), este continua dominando o financiamento habitacional. Os valores de 2012 mostram que $93 \%$ do enorme montante da dívida em habitação (R\$195.000.000.000,00) no País foi financiado pelo SFH (Cagnin, 2012, pp. 20-21).

Além disso, ao contrário da hipótese de autossuficiência do mercado privado, os recursos públicos têm sido essenciais para impulsionar o SFI, seja através de isenções fiscais (prática comum em vários países), seja, inusitadamente, através do investimento direto na compra de títulos imobiliários no mercado de capitais. Royer (2014) registrou as sucessivas mudanças de regulações do Banco Central que permitiram a captação do Fundo de Garantia do Tempo de Serviço (FGTS) - principal fonte de financiamento de habitação social e saneamento básico do País - para investimentos nesses títulos. Em 2011, o FGTS adquiriu quase $20 \%$ do valor emitido em títulos do tipo Certificado de Recebíveis Imobiliários (ibid., p. 20). A contradição torna-se maior ao se observar que a securitização imobiliária no Brasil é destinada majoritariamente ao financiamento de construções comerciais de alto padrão. Nesse sentido, a autora argumenta que o SFI tem servido para encobrir a drenagem de recursos do FGTS para os setores de mais alta renda. ${ }^{6}$ 
No que tange às transformações no planejamento urbano, ao mesmo tempo que ocorreu a emergência de uma agenda de efetivação de direitos urbanos via políticas públicas após a crise dos anos 1980, também se observou a emergência da ideia de entrada do capital privado em setores anteriormente associados ao setor público. A própria construção do Estatuto da Cidade (lei federal $n^{\circ}$ 10257/2001) ilustra bem esse cenário, com a incorporação das operações urbanas consorciadas; espécies de PPP, inspiradas nas experiências internacionais de grandes projetos urbanos.

As OUCs baseiam-se no instrumento da Outorga Onerosa pelo Direito de Construir (OODC), com a diferença de que os recursos arrecadados só podem ser investidos na área da OUC. Um formato de OODC que tem ganhado espaço é o Certificado de Potencial Adicional Construtivo (Cepac), que são títulos comercializados na bolsa de valores, em leilões públicos, que podem ser comercializados em mercados secundários, antes de serem vinculados a um empreendimento. 0 Cepac é mais um dos produtos financeiros que pretendem conectar os interesses dos agentes do mercado imobiliário (proprietários de terra, construtoras, incorporadoras, empreiteiras) e do mercado financeiro (possíveis investidores), ao mesmo tempo que visa prover os governos locais com recursos para financiar bens públicos. Esse modelo foi criado na OUC Faria Lima, aprovada em 1995, na gestão Maluf, mas só pôde ser implementado em 2004, após sua inserção no Estatuto da Cidade. Desde então, tem sido continuadamente aplicado por governos de distintos matizes ideológicos.

De acordo com a BM\&FBovespa, os Cepacs são títulos de renda variável, pois sua rentabilidade está associada à valorização imobiliária. Fix (2009, p. 53, grifo nosso) argumenta que: "com isso, cria-se a possibilidade de um novo tipo de especulação imobiliária financeirizada, com os investimentos feitos segundo os parâmetros e as expectativas próprios de uma lógica de valorização de tipo financeiro".

As OUCs com Cepac têm se disseminado gradualmente após sua inserção no Estatuto da Cidade. Conforme informações obtidas no portal da Comissão de Valores Imobiliários (CVM), até o momento, há cinco OUCs com Cepac em curso no Brasil: Água Espraiada, Faria Lima e Água Branca, em São Paulo; Porto Maravilha, no Rio de Janeiro; e Linha Verde, em Curitiba. Cabe destacar, ainda, que o Estatuto da Metrópole (lei federal $n^{\circ} 13.089 / 2015$ ) reforçou as OUCs, que agora figuram entre os instrumentos da governança metropolitana, com a possibilidade de aplicação interfederativa. Embora haja produtos financeiros com algumas características em comum, ${ }^{7}$ à primeira vista parece que o Cepac não possui um correspondente exato fora do País.

\section{Operações Urbanas Consorciadas com Cepac}

Após esse panorama inicial, analisam-se os oito artigos selecionados para discussão sobre operações urbanas consorciadas, a saber: Sánchez et al.(2004); Pessoa e Bógus (2008); Fix (2009); Nobre (2009); Alvim, Abascal e Moraes (2011); Coma (2011); Cardoso (2013); e Siqueira (2014). A análise divide-se em dois blocos. No primeiro, é discutido o arcabouço teórico dos trabalhos, suas convergências e 
divergências, bem como os possíveis diálogos com a teoria dos regimes espaciais e os debates sobre financeirização. No segundo, avaliam-se os principais agentes, suas estratégias e escalas de atuação, além das contradições decorrentes dessa disputa no (e através do) espaço.

\section{Lentes teóricas \& diálogos com a teoria dos regimes espaciais e o debate da financeirização}

De forma geral, todos os artigos selecionados reconhecem a associação entre as OUCs e a substituição do paradigma do planejamento integrado (associado ao ideário modernista) pelo planejamento estratégico, impulsionado pelas PPPs. Fix (2008, p. 52) e Siqueira (2014, p. 407) assinalam, no entanto, que, uma vez que os planos integrados nunca foram implantados na sua totalidade (funcionando na prática como "planos discurso", conforme concepção de Flávio Villaça), não é possível concluir que essa mudança se caracterize como uma ideia de abandono do plano, da mesma maneira como foi entendida nos países de capitalismo avançado.

A maioria dos autores compartilha de uma preocupação central em relação ao aumento das disparidades socioespaciais a partir das intervenções urbanas ligadas a esse ideal pós-moderno. Algumas das chaves teóricas mais recorrentes nesses trabalhos são: empresariamento urbano (Harvey); máquina do crescimento (Logan e Molotch); grandes projetos urbanos - GPUs (Swyngedouw; Moulaert e Rodriguez) e gentrificação (Neil Smith). Além disso, o tema dos megaeventos e do eventismo são recorrentes nos trabalhos sobre o Rio de Janeiro. Apesar das diferentes chaves, é possível constatar uma convergência teórica entre esses estudos; assim como é possível observar que essas leituras dialogam de forma direta ou complementar com a discussão sobre os regimes espaciais e os debates sobre a financeirização. Além disso, um dos artigos (Alvim, Abascal e Moraes, 2011) filia-se ao paradigma do Novo Urbanismo, que se distancia das abordagens anteriores, conforme discutido adiante.

A ideia de empresariamento urbano está presente como pano de fundo na maioria dos trabalhos. ${ }^{8}$ Esse conceito, da obra clássica de Harvey (1989), associa-se à tese de que está em curso uma mudança (não completada) de um modo gerencial (ou administrativo) para um modo empresarial, pós-crise do pacto fordista nos países centrais. Tal transformação se relaciona principalmente às PPPs,

tendo como principal objetivo político e econômico imediato (embora não exclusivo) mais o investimento e o desenvolvimento econômico por meio de empreendimentos imobiliários especulativos do que a melhoria das condições em um âmbito específico. (1989, p. 8; tradução nossa)

Importante ressaltar que é a concepção especulativa, que, no entender do autor, sujeita os governos locais aos perigos inerentes aos novos empreendimentos imobiliários, o que se relaciona à impossibilidade de prever "que 'pacote' terá êxito em um mundo de considerável instabilidade e volatilidade econômica" no contexto da crise global. Harvey (1989) destaca o papel do turbilhão de inovações urbanísticas que surgem nesse contexto (como os GPUs) para ampliar as fronteiras de acumulação do capital. 
Na concepção da teoria dos regimes espaciais de Brenner (2004), o autor bebeu diretamente dessa tese de Harvey, adicionando outras dimensões, como a noção de reescalonamento do Estado. Ou seja, além de uma mudança da forma de gestão, ocorre um processo de mudança da escalaridade do Estado, tanto escalas de organização como de intervenção. Os GPUs são um claro exemplo disso. 0 Estado passa a privilegiar áreas pontuais, abandonando a visão abrangente do território; além disso, passa a criar agências estatais específicas (enclave agencies) para cuidar desses territórios, que podem contribuir para a fragmentação da gestão e ampliação da seletividade de atuação territorial do Estado. Podemos citar, como exemplo, a criação da Companhia de Desenvolvimento Urbano da Região do Porto do Rio de Janeiro (CDURP) para gerir a operação da OUC Porto Maravilha (Cardoso, 2013).

0 conceito da máquina de crescimento, originalmente desenvolvido por Logan e Molotch (1987), é trabalhado com maior ênfase nos artigos de Fix (2009) e Cardoso (2013). 0 conceito refere-se à leitura de que, por trás dos projetos de redesenvolvimento urbano, há uma rede de agentes das mais diversas naturezas (proprietários de terra, órgãos públicos, fundos de pensão, incorporadoras, mídia, bancos, empresas de crédito, construtoras, políticos, indústria cultural, entre outros) que se unem em torno do ideal de se beneficiar com a valorização imobiliária. Esse intuito se choca com o interesse na promoção de um bem comum, que, via de regra, acompanha as justificativas de tais projetos urbanos.

A partir dessas premissas, os trabalhos concentram-se na avaliação de como são estruturadas essas coalizões pró-crescimento, quem são e quais suas estratégias para driblar possíveis entraves à captura das rendas fundiárias. Fix (2009) e Cardoso (2013) demonstram como se consolidou uma parceria de diversos agentes para impulsionar a valorização das áreas onde se localizam as operações Água Espraiada e Porto Maravilha, respectivamente. Isso significou, por exemplo, ações conjuntas para deslocar a população pobre residente, além da priorização de investimentos em obras rodoviaristas e de apelo estético, em detrimento de investimentos em habitação social, que poderiam comprometer a valorização imobiliária.

Como se fosse um "buraco negro" atraindo tudo ao seu redor, o critério de "valorização financeira" extrai a sua potência da submissão dos elementos formadores do próprio espaço: a natureza (a paisagem da Baía de Guanabara), a cultura, 0 ambiente construído através da instalação das infraestruturas urbanas. (Cardoso, 2013, p. 83)

Interessante apontar uma diferença destacada por Mariana Fix em relação à composição das coalizões no Brasil, no que se refere à ausência de um sistema de crédito "que desempenhe o papel fundamental de coordenador das funções, atuando como uma espécie de 'sistema nervoso' que regula os movimentos do capital" (Fix, 2009, p. 57). Tanto Fix (ibid.) como Cardoso (2013, p. 81) apontam que, no Brasil, os fundos de pensão nacionais têm constituído atores-chave na substituição do sistema crédito. Esses fundos têm sido fundamentais para dar a liquidez necessária a vários megaempreendimentos nas áreas das OUCs, tanto no caso da Faria Lima (FL), como da Água Espraiada (AE) e de Porto Maravilha 
(PM). Fix (ibid.) comenta alguns dos impactos da participação desse agente na tipologia e no perfil dos empreendimentos imobiliários priorizados nessas áreas:

Essa participação tem impacto no projeto arquitetônico dos edifícios e em sua localização na cidade. Os fundos de pensão tratam a terra como um ativo financeiro, de modo a ter acesso a rendimentos futuros. Não é por acaso que os alvos dos fundos são os edifícios de mais alto padrão, classificados como A, duplo A, ou triple A.

Essa abordagem de Logan e Molotch (1987) fornece uma metodologia consistente para identificar os tipos de agentes e a forma como disputam a produção das cidades. Cabe destacar, no entanto, que essa tese foi objeto de amplo debate crítico no cenário internacional, que culminou no livro The urban growth machine. Critical perspectives two decades later. Uma das críticas refere-se a um enfoque demasiado na escala local, ou seja, um negligenciamento das coalizões supralocais. A articulação dessa chave teórica com a teoria dos regimes espaciais, de claro viés multiescalar, pode ser promissora, a fim de cobrir lacunas das duas abordagens. A abordagem dos regimes espaciais também é comumente alvo de críticas em relação ao seu caráter estruturalista, seu intuito de promover leituras generalizantes, o que pode incorrer no risco de deixar escapar as especificidades dos processos locais. As categorias de análise dos agentes propostas por Logan e Molotch podem ajudar no sentido de dar maior concretude aos processos analisados.

A abordagem dos Grandes Projetos Urbanos (GPUs), mais debatida nos trabalhos de Sánchez et al. (2004) e Coma (2011), identifica tais projetos como os elementos mais representativos da história recente de produção do espaço urbano, que são entendidos como forma de subordinação do ambiente construído aos ditames dos novos circuitos do capitalismo globalizado. As OUCs são reconhecidas como exemplos paradigmáticos dos GPUs no Brasil. 0 Estado possui uma centralidade nessas leituras, como um elemento-chave organizador do complexo de forças que engendra os GPUs, através de "um conjunto - homogêneo - de orientações que passam a compor uma pauta a ser buscada e colocada em prática pelos diversos administradores urbanos, independentemente de sua filiação político-partidária" (Sánchez et al., 2004, p. 42).

Com esse ponto de partida, Sánchez et al. (ibid.) enfocam o estudo da convergência entre as principais técnicas discursivas e materiais utilizadas pelo poder público em 14 GPUs nos Estados Unidos, Europa e América Latina, incluindo duas operações urbanas (em Niterói e Rio de Janeiro). Coma (2011), por sua vez, debate a noção de "excepcionalidade" (que se refere ao estado de exceção e urgência que perpassa grande parte dos GPUs), que, de acordo com Swyngedou (2002), aparece como estratégia recorrente para justificar violações de direitos urbanos. Os dois artigos trabalham mais no sentido do que há de convergente entre os GPUs, do que de suas especificidades em relação aos diferentes contextos políticos e econômicos.

A chave teórica dos GPUs dialoga com a teoria dos regimes espaciais, na medida em que contribui para identificar como estratégias e projetos do Estado vêm sendo moldados, a partir dos novos ideários sobre a política urbana. Observa-se, a princípio, uma possibilidade 
de potencializar essa abordagem ao relacioná-la com alguns pressupostos da teoria dos regimes espaciais, como o papel relacional entre a disputa dos atores para capturar estratégias e projetos estatais (e vice-versa); o que poderia contribuir para entender as diferenças que os GPUs podem assumir em cada contexto geográfico e político.

0 eventismo e os megaeventos - discutidos no artigo de Coma (2011) a partir de Hiller (2000), Gaffney (2010) e outros - relacionam-se aos grandes eventos internacionais (a exemplo dos grandes eventos esportivos) que são considerados catalisadores da implantação da agenda neoliberal urbana. Aproveitando-se do discurso supostamente neutro e universal do esporte, os eventos facilitam a implantação dos projetos a partir de regimes de governança de caráter excepcional. Coma (2011) identifica esse estado na realização dos grandes eventos esportivos recentes no Rio de Janeiro, como indica a votação do projeto da OUC-PM em menos de um mês após o anúncio da vitória da cidade como sede das Olimpíadas de 2016. Ressalta-se, em relação ao debate da espacialidade do Estado, o caráter transnacional que esses eventos representam em associação às coalizões locais:

Siguiendo a Surborg et al. (2008) estos mega eventos deportivos requieren de una aproximación bidireccional - global y local - que de cuenta de lãs dimensiones transnacionales de la máquina de crecimiento urbano, en la medida en que éstos plantean una versión de máquina de crecimiento selectivamente transnacional y local cuya función principal es equilibrar el poder político tradicional de las coaliciones de desarrollo local, con La necesidad de responder a actores $y$ coaliciones extra-territoriales, lo que denomina una diáspora de la máquina de crecimiento. (Coma, 2011, p. 215)

0 conceito de gentrificação - adotado no artigo de Siqueira (2014), a partir de Smith (2002) e de outros autores - é definido (em sua concepção contemporânea) como o processo de redesenvolvimento urbano que acarreta na elitização socioespacial. Uma ideia importante é a possibilidade de lucrar com a renda diferencial propiciada pela dinâmica de investimento e desinvestimento no espaço (rent gaps). Um exemplo disso é o caso do redirecionamento dos investimentos públicos e privados nos EUA para os subúrbios, com o consequente abandono e popularização do centro, e posterior retorno de investimentos, ocasionando no enobrecimento dessa área. ${ }^{9}$ Essa dinâmica que ocorreu nos EUA faz parte da primeira onda de gentrificação - assim caracterizada por Hackworth e Smith (2001) -, já a terceira onda em curso é caracterizada pela intensificação dos processos de gentrificação através de estratégias que envolvem "novos produtos imobiliários em localizações já fora dos bairros adjacentes aos centros urbanos" (Siqueira, 2014, p. 397).

Siqueira (ibid.), entretanto, chama atenção para as diferentes geografias de investimento/desinvestimento. Nesse sentido, ela compreende que o Brasil (e outros países emergentes como a Índia e na Ásia) não teria vivido de forma clara a primeira fase, visto que os centros urbanos não tiveram um desinvestimento tão abrupto como nos EUA. A partir disso, ela defende que os melhores exemplos para estudar a gentrificação no Brasil seriam as OUCs e não os processos de revitalização de áreas centrais. Siqueira (ibid.) analisa as OUCs 
FL e AE em São Paulo e constata a presença de três processos comuns às dinâmicas de gentrificação: produção de espaço gentrificável (existência de condições para que seja possível extrair renda diferencial); elitização social com expulsão dos grupos vulneráveis; e transformação na paisagem construída (produção de ícones arquitetônicos, uso de novos estilos arquitetônicos com referência estética pós-moderna, entre outros).

0 paradigma do Novo Urbanismo, discutido por Alvim, Abascal e Moraes (2011) com base em Ascher (2010), defende que o planejamento estratégico possui vantagens (como maior adaptação às crises, através de um modelo de intervenção mais flexível com um programa de curto prazo) em relação ao modo tradicional de planejamento (planejamento integrado). Tais vantagens, se bem geridas, poderiam contribuir decisivamente para amenizar as contradições urbanas e conferir maior qualidade urbanística às cidades, no entendimento dos autores.

[...] um novo urbanismo ou neourbanismo, conforme denominação de Ascher (2010), visa à realização de objetivos incentivando atores públicos e privados a estabelecer parcerias, a fim de potencializar os efeitos e 0 alcance social das propostas. (...) Na sociedade contemporânea, em que as cidades assumem papel protagonista para a realização do processo econômico, é incabível pautar o desenvolvimento urbano em planos e projetos definidos como programas de longo prazo, como fora prática consagrada durante os anos de vigência do paradigma moderno. Ascher (ibid.) conclama a definir um novo urbanismo, reflexivo e adaptado à sociedade complexa e de futuro incerto. (Ibid., pp. 215-216)
A preocupação central do trabalho de Alvim, Abascal e Moraes (2011) relaciona-se à não efetivação de um projeto urbano consistente na operação urbana Água Branca. Esses autores entendem que, nesse caso, as vantagens do novo modelo de urbanismo não estão sendo traduzidas em ganhos sociais ou melhoria da qualidade urbanística. Eles atribuem um peso grande disso à ausência de um projeto urbano capaz de articular os diversos interesses.

Embora os objetivos enunciados pela lei n 11.774/1995 [Lei da OUC Água Branca] fossem incentivar a ocupação das áreas vazias e reestruturar 0 adensamento com novos padrões de uso e ocupação do solo, atraindo principalmente investimentos dos setores privados, a ausência do projeto urbano como importante instrumento de interlocução entre Prefeitura, empreendedores, proprietários e moradores pode ser detectado como importante problema. (Ibid., pp. 215-216)

A despeito da filiação teórica dos autores, entende-se que as abordagens anteriores poderiam contribuir para iluminar algumas de suas preocupações. Um olhar atento às coalizões que promovem as OUCs, por exemplo, elucidaria que os interesses hegemônicos que as movem estão bem coordenados em certos casos. As OUCs FL e AE, como exemplo, conseguiram articular interesses de entes públicos e privados para impulsionar grandes intervenções urbanas, igualmente sem um projeto urbano de qualidade. ${ }^{10}$

Além disso, cabe apontar que, no período em que foi escrito este artigo, a área da operação Água Branca ainda não era um vetor de grande interesse do mercado imobiliário como tem se constituído nos últimos anos, o que 
pode ajudar a explicar o insucesso até aquele momento em promover grandes transformações na sua área. Não se trata de relegar a importância do projeto urbano, mas de entender que a concretização de "bom projeto" estaria relacionada a uma coalizão e a um regime espacial e de acumulação que priorizem tais parâmetros projetuais qualitativos (ou interesses coletivos) em detrimento de uma lógica orientada pela valorização imobiliário-financeira.

Com relação ao tema da financeirização, uma constatação comum à parte dos trabaIhos é a identificação de que, com o avanço da neoliberalização, há uma nova relação e maior imbricação entre os capitais financeiro, imobiliário e o Estado (Sánchez et al., 2004; Fix, 2009; Coma, 2011; Cardoso, 2013; e Siqueira, 2014). Essa relação se estabelece na medida em que o capital imobiliário passa a servir mais à reprodução do capital financeiro, do que o inverso, anteriormente mais comum. Uma expressão disso seria a constatação comum nesses trabalhos de que os GPUs se orientam mais pelo impulso de valorizar a terra. Dessa forma, valorizam-se todos os ativos financeiros a ela vinculados, sejam os Cepacs, os fundos de investimento imobiliários (FIIs) ou outros tipos de títulos lastreados em imóveis na área das OUCs.

Nem todos os trabalhos, no entanto, buscam responder como ocorre esse fluxo de recursos de um circuito do capital para o outro, com algumas exceções. Fix (2009) discute a sobreposição dos Flls às áreas das OUCs FL e AE. Apesar de os Flls não constituírem parte do arranjo financeiro dessas OUCs, por meio deles os seus acionistas (nacionais e internacionais) ${ }^{11}$ no mercado de capitais podem participar da captura das rendas fundiárias, sem precisar (a priori) manter nenhum envolvimento direto com a produção daqueles lugares.

Já o arranjo da OUC-PM, conforme discutido por Cardoso (2013), envolveu a constituição de um megafundo de investimento imobiliário coordenado pelo FGTS (FI-FGTS), que adquiriu todo o estoque de Cepac por 3,5 bilhões, além dos terrenos públicos da OUC. ${ }^{12}$ Como contrapartida, o FI-FGTS assumiu a reponsabilidade de arcar com todo o custo de obras e serviços públicos vinculados à OUC (originalmente orçado em oito bilhões), o que dependeria do sucesso da valorização dos títulos e terrenos. Para atingir tal intuito, além de garantir a remuneração do próprio FGTS, a autora observa que as diretrizes de investimento do fundo têm priorizado a negociação dos terrenos e Cepacs com empreendimentos com maior capacidade de alavancar a valorização, ${ }^{13}$ distantes das necessidades de uma das metrópoles que concentra os maiores déficits sociais do País. A partir disso, Cardoso (2013, p. 79) entende que:

As diretrizes expostas evidenciam que a terra se transformou em um ativo financeiro. Logo, o princípio básico que move toda a dinâmica de produção do espaço na área da OUC do Porto do Rio, operação esta assentada sobre um fundo de investimento imobiliário, é a rentabilidade. Como consequência, os resultados serão medidos, projetados e avaliados a partir desse princípio.

Cabe destacar, ainda, que, no caso do Porto Maravilha, a negociação de parte dos Cepacs tem sido elaborada por meio da troca dos títulos por cotas em Flls de imóveis que 
estão sendo erguidos na área da OUC. Essa experiência demonstra maior e mais complexa relação entre o imobiliário e o financeiro, na qual o Cepac constitui um veículo facilitador (tendo em vista o vínculo de sua rentabilidade com o rendimento dos Flls). Surpreende, no entanto, o fato de que aquele que cumpre o papel do principal investidor dos títulos (FI-FGTS) se confunda com o próprio Estado. Novamente, evidencia-se o uso do discurso e dos arranjos próprios da financeirização para escamotear a drenagem de recursos públicos para os setores de maior renda.

É notável, contudo, a ausência de análises mais detalhadas a respeito do Cepac na experiência paulista no que corresponde à formação de um mercado de investidores do título na bolsa de valores. Embora haja evidências de que esse mercado seja pequeno, ${ }^{14}$ não há dados que permitam avaliar possíveis tendências (como a evolução do número e do valor das transações, perfil dos compradores, entre outros) e suas motivações. ${ }^{15}$ Essa análise poderia contribuir para entender em que medida 0 Cepac está facilitando a penetração dos agentes financeiros nesses casos. Mesmo que não haja um mercado secundário desenvolvido, o arranjo institucional do Cepac pode favorecer a um acirramento da lógica de gestão orientada pela rápida valorização imobiliária, na medida em que a possibilidade tanto de haver correção do seu valor mínimo nos sucessivos leilões, como de promover maior interesse na compra do título (tendo em vista financiar as intervenções previstas) está atrelada à dinâmica de valorização imobiliária.
Agentes, estratégias, escalas e contradições

Sanchez et al. (2004) enfocam a análise das estratégias discursivas e programáticas comuns à 14 GPUs estudados em diversos países - do norte e sul global - e como o Estado é moldado por elas. Uma tática recorrente para a defesa dos GPUs como motores da transformação urbana é a desqualificação do "outro" (do planejamento integrado, ou das cidades e regiões que sigam outros modelos). Algumas das palavras de ordem, propagadas pelo uso do citymarketing para caracterizar o novo são: "sinergias", "competitividade", "parcerias", "sustentabilidade" (ambiental e financeira), "pertencimento", "cidadania" e "eficiência" (2004, p. 42). Os trechos destacados por Coma (2011, p. 218) da fala do então prefeito do Rio de Janeiro (Eduardo Paes), sobre os objetivos da OUC-PM, são simbólicos nesse sentido: "recuperar as origens do Rio e a autoestima do centro da cidade" como "instrumento de reversão da decadência".

Os autores entendem que, através dessa "luta simbólica para impor determinada visão de mundo associada a um modelo", os discursos atuam sobre o campo das práticas, reelaborando-as (Sánchez et al., 2004, p. 44). Desse modo, as sinergias e parcerias são traduzidas na busca da construção de consensos (no lugar do reconhecimento dos conflitos) "para que todos possam se beneficiar da nova cidade gerencial (2004, p. 48)". A convergência programática dos GPUs é resumida, em linhas gerais, por Sánchez et al. (2004, p. 51) pela: 
[...] combinação de investimentos públicos e privados para a construção de novos equipamentos culturais e de serviços, ampliação do número de empreendimentos com fins habitacionais próximos aos centros financeiros e comerciais e criação de áreas públicas junto ao mar. A partir daí, segundo a retórica oficial dos projetos, o êxito seria medido por vários critérios: desde 0 aumento da receita com 0 turismo e do índice de emprego até o melhoramento da qualidade de vida e elevação da autoestima dos habitantes.

Nesse sentido, a OUC-PM se encaixa nos projetos waterfront, enquanto as OUCs FL e AE tratam da criação de um novo centro financeiro, com produção de unidades habitacionais principalmente voltadas à população de alta renda.

Sánchez et al. (2004) também indicam que a ideologia do novo ganha base material no uso da arquitetura espetacularizada, através da disseminação de projetos de grife. Entre os projetos de caráter simbólico que expressam o "novo", Fix (2009) e Siqueira (2014) destacam a estética pós-moderna dos megaempreendimentos ao longo das marginais do Rio Pinheiros, e, especialmente, a famosa ponte estaiada (inspirada nas pontes do starchitect Santiago (alatrava), nas operações AE e FL. Já a OUC-PM conta com o Museu do Amanhã, de autoria do próprio Calatrava. Fix (2009) ressalta a contradição que representam essas táticas transpostas aos países emergentes:

Nesses países, que se encontram em uma situação intermediária na hierarquia do sistema mundial, a produção dessa base exige a concentração de investimentos públicos e privados capazes de, mesmo com um padrão de acumulação mais baixo, mimetizar os padrões encontrados nas cidades dos países centrais. A sua produção coloca em funcionamento uma máquina imobiliária de crescimento que procura associar seus empreendimentos à imagem de uma cidade "globalizada", da "classe mundial", ou de "primeiro mundo". (lbid., p. 61)

0 Estado (nas diversas escalas) é, certamente, uma das forças mais analisadas nos trabalhos. Dentre suas atuações, a mais discutida é aquela em que ele provê o suporte institucional, regulatório e de financiamento. Além da atuação na criação das leis locais, Fix (2009) e Siqueira (2014) assinalam a importância da inclusão das OUCs no Estatuto da Cidade para a disseminação do modelo; e Siqueira (2014, p. 407) assinala algumas conexões interessantes que possivelmente contribuíram para inserção das operações na lei nacional. A partir da leitura das atas da comissão em que a lei foi discutida na câmara legislativa, essa autora observa que o relator da lei federal (do mesmo partido de Paulo Maluf) tece agradecimentos ao então secretário de planejamento de São Paulo, Gilberto Kassab (posteriormente prefeito na mesma cidade e Ministro das Cidades) a respeito da implantação da OUC-FL. Ainda sobre a inserção do tema no Estatuto, Fix (2009, p. 52) chama a atenção para a relevância do respaldo de determinados setores identificados com o urbanismo dito progressista, ao caracterizar as operações como um mecanismo de recuperação das mais-valias urbanas.

Uma questão central em diversos trabalhos é o peso dos recursos públicos (principalmente municipais e federais) para a sustentação financeira das operações, através de recursos humanos (funcionários, gestores para 
operar os projetos) ou materiais (terrenos, recursos financeiros, isenções fiscais). Fix (ibid.) destaca a importância das obras feitas diretamente com recursos municipais previamente à implementação da OUC-AE (como o custo de mais de um bilhão com a canalização do córrego Espraiada e a abertura da avenida Roberto Marinho, além dos recursos com a remoção das favelas), que recorrentemente são escamoteadas nos cálculos para aferir o sucesso da operação. Fix (ibid., p. 47) chama atenção ao dado de que $85 \%$ dos investimentos públicos em infraestrutura urbana em São Paulo na década de 1990 se concentraram na área ou nas proximidades das duas operações.

No caso do Rio de Janeiro, a captura dos recursos públicos é ainda mais explícita. Cardoso (2013, pp. 74-79) destaca que $75 \%$ dos terrenos disponíveis para intervir na operação são de propriedade pública (principalmente da União) e que a primeira fase da operação contou com 350 milhões (financiados pela Prefeitura e pelo Ministério do Turismo). Ademais, a segunda fase ${ }^{16}$ ficou toda por conta do $\mathrm{FI}$ -FGTS, conforme anteriormente discutido; ou seja, parte substancial dos riscos financeiros ficou a cargo do fundo constituído pelo conjunto dos trabalhadores do País. ${ }^{17} 0$ alinhamento político entre o prefeito, o governo estadual e o governo federal, nos anos iniciais da OUC, foi certamente determinante para facilitar essa convergência de recursos, como argumenta Coma (2011).

Além de colocarem em xeque a suposta autossuficiência financeira das operações através da arrecadação dos Cepacs, ou mesmo um possível equilíbrio entre os investimentos públicos e privados, esses exemplos evidenciam que não somente as cidades ditas globais (como Rio de Janeiro e São Paulo) têm sido fundamentais na propagação dos GPUs, mas também o Estado nacional tem sido essencial para alavancá-los.

Vale relembrar, ainda, a captação de recursos dos fundos de pensão e de previdência para financiar os megaempreendimentos nas OUCs, revelando as várias frentes simultâneas de especulação com os recursos oriundos dos trabalhadores. 0 fundo imobiliário do Centro Empresarial Nações Unidas, um grande empreendimento comercial de luxo na OUC-AE, tem como principal cotista o fundo de pensão dos trabalhadores da Caixa Econômica Federal (Fix, 2009), em 2016, o terceiro maior fundo de pensão do Brasil. Já Cardoso (2013) discute a participação do fundo de previdência dos funcionários da prefeitura do Rio de Janeiro (Previ-Rio) em empreendimentos imobiliários na zona portuária.

Cabe destacar a atuação do poder público municipal em conjunto com agentes imobiliários, no deslocamento da população pobre da área das operações. 0 que é entendido, por Fix (2009) e Cardoso (2013), como forma de não comprometer a valorização imobiliária que poderia ser arrefecida no caso de uma ocupação social mais equilibrada. Fix (2009) destaca que, anteriormente à OUC-AE, durante a construção da Av. Roberto Marinho, houve um processo intenso de remoções no local (onde havia cerca de 20 mil famílias residentes em favelas), através principalmente de indenizações, insuficientes para comprar uma casa em outra área irregular (Fix, 2009, p. 50). A ação do poder público foi acompanhada da coação pelos empreendedores, bem como, do próprio aporte em recursos de 122 empresas para financiar uma parcela das indenizações (Fix, 2009, p. 45; 
Nobre, 2009, p. 207). Os poucos moradores que conseguiram resistir, voltaram a ser coagidos após o início da operação. Destaca-se o caso dos moradores da favela Jardim Edith, que só conseguiram o direito de ser atendidos (ao menos em parte) dentro do perímetro da operação, após intensa mobilização e terem recorrido às instâncias judiciais (Fix, 2009).

Siqueira (2014) adverte que o Jardim Edith se tratava de uma Zona Especial de Interesse Social (Zeis), o que reforça a contradição do intuito de removê-la. Além disso, a autora assinala a importância de instrumentos como este, no sentido de reforçarem a argumentação nas disputas judiciais pela permanência das populações, fato que, de acordo com ela, "não se verifica naqueles países de casos tradicionais de gentrificação" (2014, p. 408). Casos semeIhantes têm sido observados em outros projetos de renovação, como será discutido adiante. Associada a essa dinâmica, Pessoa e Bógus (2008) constatam, através dos dados do censo demográfico, uma diminuição de população nas localidades equivalentes a OUCs FL e $A E$, ao mesmo tempo que revelam que as maiores taxas de incremento demográfico têm acontecido nas periferias da cidade. Nesse sentido, poderíamos dizer que a nova paisagem verticalizada que poderia sugerir um maior número de pessoas usufruindo os benefícios dos investimentos esconde uma verdadeira "cidade oca" (termo cunhado por Nakano, 2015) para usufruto de uma minoria privilegiada.

Cardoso (2013) constata que, a despeito dos inúmeros documentos oficiais que apontam como prioridade a provisão habitacional de interesse social na OUC-PM, não foram divulgadas propostas para atender à questão, em que pese a imensa quantidade de terrenos públicos que poderia se destinar para esse fim. A autora ressalta que a favela do Morro da Previdência, localizada na área da operação, foi objeto de um projeto de urbanização - no âmbito do Programa Morar Carioca - que iniciou a remoção de 800 famílias para áreas periféricas, mesmo a favela sendo uma Área Especial de Interesse Social (Aeis). Da mesma forma que ocorreu no Jardim Edith, os moradores precisaram recorrer à defensoria, o que resultou na suspensão das intervenções, ao menos temporariamente.

A autora chama a atenção para as sobreposições de papéis das grandes empreiteiras e construtoras que atuam na região portuária, já que o mesmo grupo que ganhou o consórcio para operar a segunda fase da OUC-PM venceu a concorrência do Morar Carioca. ${ }^{18}$ Cabe destacar ainda que boa parte dessas empresas, e outras que atuam nas áreas das operações, construindo infraestrutura ou edifícios, possui capital aberto na bolsa. 0 que significa que os interesses que cercam as OUCs devem responder, ainda, aos critérios de lucratividade dos acionistas dessas empresas (em diversas partes do mundo).

Além disso, Cardoso (2013, p. 95) ressalta o papel de resistência das populações afetadas por esses grandes projetos, como um contraponto importante ao processo de dominação, e destaca a atuação do Fórum Comunitário do Porto, que tem denunciado o caráter excludente das intervenções na região portuária.

Outros agentes que aparecem nas análises são os órgãos multilaterais, como importantes difusores dos modelos dos GPUs, seja através de sua divulgação como best practices, seja no financiamento de projetos desse cunho. Revela-se, portanto, o caráter transnacional da nova política urbana. Várias operações 
urbanas no Brasil possuem como inspiração direta as experiências estrangeiras: documentos da OUC-PM revelam inspiração nos projetos realizados para as olimpíadas em Barcelona (Cardoso, 2013), assim como Battery Park é citado como referência para as operações em São Paulo (Siqueira, 2014). Na mesma linha, os megaeventos e a rede de organizações e capitais envolvidos na sua promoção aparecem como importantes disseminadores, agindo, nas palavras de Coma (2011), como catalisadores (impondo temporalidades e modelos de gestão excepcionais) e vetores de consenso da agenda de renovação urbana.

Uma leitura recorrente nos trabalhos a respeito das contradições das OUCs refere-se à constatação de que elas só têm obtido êxito (no sentido de arrecadação) quando coincidem com as áreas de interesse imobiliário, em que geralmente há uma melhor provisão de infraestrutura, incorrendo em um círculo vicioso de investimento em áreas já privilegiadas (Sánchez et al., 2004; Pessoa e Bógus, 2008; Fix, 2009; Nobre, 2009; Cardoso, 2013; e Siqueira, 2014). As operações debatidas neste artigo são claros exemplos disso. A OUC-FL e a OUC-AE localizam-se no setor sudoeste - reduto tradicional da elite paulistana - e a OUC-PM localiza-se em uma das poucas áreas existentes para expansão imobiliária na região central do Rio de Janeiro.

Além disso, as operações urbanas Centro e Água Branca, em São Paulo, são tidas, geralmente, como casos de insucesso de arrecadação. Há indícios, no entanto, de mudanças nesse quadro. Pesquisas recentes (Sígolo, 2014) sobre a dinâmica do boom imobiliário da última década evidenciam novos vetores de atuação do mercado imobiliário na metrópole paulistana, como um retorno para o centro, uma expansão no sentido sudeste, sobre os municípios da região do Grande $A B C$, além de um crescente interesse nos grandes terrenos localizados em orlas ferroviárias. Não à toa, articuladas a esse processo, começam a surgir propostas de novas OUCs ou revisão dos parâmetros de operações antigas, exatamente nesses novos eixos. $A$ OUC-AB, localizada em área lindeira à ferrovia, foi revisada em 2013 e teve o seu primeiro leilão de Cepac em 2015. Ao mesmo tempo, está sendo discutida a lei da operação Bairros do Tamanduateí, localizada em uma área de orla ferroviária no vetor sudeste, divisa com o $A B C$ paulista. Recentemente, o município da região do $A B C$ que mais teve lançamentos imobiliários na última década, São Bernardo do Campo, teve uma OUC aprovada, que já se encontra em processo de aprovação na CVM.

Por fim, parece unânime a constatação quanto à ausência de um projeto urbano de qualidade nas operações estudadas (Alvim, Abascal e Moraes, 2011; Fix, 2009; e Coma, 2011). Os projetos são muito mais detalhados nas definições em relação aos coeficientes de aproveitamento do que nas definições em relação ao desenho urbano.

\section{Considerações finais}

A partir da análise dos artigos, argumenta-se que a teoria dos regimes espaciais, em diálogo com outros debates teóricos (como o empresariamento urbano, a máquina do crescimento, as vertentes que analisam os grandes projetos urbanos, os processos de gentrificação e os impactos dos megaeventos), parece promissora para iluminar os impasses atuais da política urbana no contexto da dominância financeira 
global e de desestruturação do Estado Nacional Desenvolvimentista no Brasil, ao relacionar as alterações na forma de organização e intervenção do Estado com as lutas dos agentes e as transformações no regime de acumulação. Enquanto a ótica do Novo Urbanismo, parece relegar esses aspectos que poderiam ser úteis para entender os entraves da concretização de projetos urbanos orientados por uma lógica de universalização de bens coletivos.

No que se refere ao debate da financeirização, observa-se que a visão que tem guiado a implementação das OUCs atualmente tem sido mais a noção da terra como um ativo financeiro, do que uma busca pela suposta recuperação das mais-valias aos cofres públicos, com o seu reinvestimento sob a ótica da redistribuição ou inclusão social. Foram discutidos, ainda, alguns expedientes que têm facilitado os nexos entre o financeiro e o imobiliário, como os Flls que se concentram nas áreas das OUCs, além do arranjo financeiro da OUC - que envolveu a constituição do FI-FGTS, que tem negociado os ativos da OUC (Cepacs e terrenos) guiados prioritariamente pelo princípio rentabilidade, distanciando o projeto de renovação das necessidades básicas da maior parte da população carioca. Destacou-se, também, ausência de análises mais detalhadas sobre as dinâmicas do Cepac no mercado secundário e suas motivações. Ainda que tal mercado seja pequeno, essa análise poderia contribuir para entender em que medida o Cepac está facilitando a penetração dos agentes financeiros na produção do espaço nas OUCs.

Algumas das principais contradições socioespaciais levantadas referem-se à incompatibilidade de se conciliar os objetivos de valorização imobiliária ao atendimento das demandas coletivas, visto que, apesar do discurso recorrente de atendimento ao déficit habitacional, observa-se uma dinâmica intensa de gentrificação em curso nas áreas das OUCs. Observa-se, ainda, uma dinâmica de esvaziamento populacional em algumas OUCs, diferentemente do que a paisagem verticalizada poderia sugerir.

No que diz respeito aos agentes e suas estratégias, abordaram-se as práticas discursivas comuns que acompanham as narrativas sobre os GPUs, que envolvem a desqualificação de outros modelos de intervenção, como contraponto ao novo. A ideia de modernização é ainda reforçada simbolicamente através da arquitetura pós-moderna e de projetos de grife. A convergência programática dos GPUs, com a prescrição de um modelo independente do contexto socioespacial em que incidem, foi outro aspecto destacado. Em relação ao Estado, além do seu papel no suporte regulatório, discutiu-se sua atuação central no financiamento das OUCs, por meio de recursos e terras, em distintas fases de implementação e mediante vários níveis de governo e diferentes agências governamentais (com o FGTS se consolidando como uma arena de disputa importante). A respeito do financiamento, os fundos de pensão e de previdência (públicos e privados) emergem enquanto um importante agente na sustentação financeira dos megaempreendimentos nas áreas das OUCs. Discutiu-se, também, a atuação do Estado em articulação com empreendedores em ações de deslocamento da população de baixa renda; enquanto o papel de resistência das populações afetadas aparece como um contraponto importante a esse processo. A sobreposição de papéis das grandes empresas de infraestrutura 
em contratos nas áreas das OUCs também chama a atenção. Foi abordado, ainda, o papel de organizações multilaterais e de agências envolvidas nos megaeventos esportivos enquanto importantes disseminadores e catalisadores do modelo dos GPUs.

Observa-se, contudo, a ausência de informações sobre alguns agentes, o que suscitou alguns questionamentos: "Qual a influência em relação ao desenho e implementação das OUCs dos agentes do mercado financeiro (como corretores que intermedeiam a compra do Cepac no mercado de capitais, os funcionários da bolsa de valores que operam os leilões)?"; "Qual o papel do agente que coordena a emissão e a distribuição do Cepac?"; "Quais as influências das empresas de consultoria que assessoram a elaboração da modelagem financeira e urbanística das OUCs?". A compreensão desses questionamentos poderia contribuir para complementar o entendimento de outros fatores e interesses envolvidos nas disputas sobre a promoção das OUCs. As lacunas aqui identificadas constituem parte de uma agenda de pesquisa em curso e serão objetos de debate em trabalhos futuros.

\section{Laisa Eleonora Maróstica Stroher}

Faculdades Integradas Alcântara Machado/Faculdades de Artes Alcântara Machado, Curso de Arquitetura e Urbanismo. São Paulo, SP/Brasil.

laisaeleonora@gmail.com

\section{Notas}

(1) Este artigo integra uma pesquisa de doutorado em curso sobre as Operações Urbanas Consorciadas na Região Metropolitana de São Paulo, orientada pelo professor Jeroen Klink, no Programa de Pós-Graduação em Planejamento e Gestão do Território na Universidade Federal do ABC. A primeira versão deste artigo foi apresentada como trabalho final da disciplina "Práticas de planejamento e gestão dos territórios", ministrada pelas professoras Rosana Denaldi e Sandra Momm. Agradeço aos comentários das professoras, do meu orientador e dos pareceristas da revista Cadernos Metrópole, que contribuíram para aprimorar o resultado aqui apresentado.

(2) O conceito de Estado Desenvolvimentista utilizado alinha-se à definição de Gonçalves (2012, p. 6), que o entende, resumidamente, como: "projeto de desenvolvimento econômico assentado no trinômio: industrialização substitutiva de importações, intervencionismo estatal e nacionalismo".

(3) Busca elaborada em janeiro de 2016.

(4) Alguns dos exemplos recorrentes referem-se ao privilegiamento de empreendimentos voltados a escritórios de alto padrão em prejuízo do direcionamento para habitação, especialmente para a população de menor renda. 
(5) Ao mesmo tempo que as altas taxas de juros, parte do mesmo pacote, acederam às críticas sobre os efeitos em termos de desindustrialização e da financeirização da economia (Paulani, 2008).

(6) Em apresentação recente (na VII Conferência Anual de Economia Política, em setembro de 2016, em Lisboa), a autora mostrou dados atualizados que demonstram que os recursos do FGTS investidos em títulos imobiliários superam atualmente o utilizado para subsidiar a política habitacional de interesse social.

(7) Como é o caso do Tax Increment Financing (TIF), utilizado nos Estados Unidos, que se refere à securitização da expectativa de valorização futura da arrecadação de impostos locais sobre a propriedade fundiária e imobiliária em áreas voltadas a projetos de renovação urbana (ver Weber, 2010).

(8) Especificamente nos trabalhos de: Sánchez et al. (2004); Fix (2008); Coma (2011); Cardoso (2013) e Siqueira (2014).

(9) Portanto, o lucro foi obtido primeiro transformando as terras rurais em subúrbio, depois com a valorização do centro.

(10) Qualidade nos termos que Alvim, Abascal e Moraes entendem: com inserção social, preocupação central em termos de mobilidade a pé e por transporte não motorizado. Ademais, as duas operações possuem apenas uma lista de intervenções, o que não configura um projeto.

(11) Pesquisa em curso, conduzida pelo LabCidade da USP, demonstra que, apesar de os investidores dos Flls nessas áreas serem na maioria nacionais, há uma presença também de agentes internacionais, conforme apresentação de Paula Santoro na VII Conferência Anual de Economia Política, em setembro de 2016, em Lisboa.

(12) Em 2016, o FI-FGTS era o Fll com maior patrimônio líquido do País, segundo informações obtidas no portal da CVM.

(13) Como empreendimentos comerciais e de escritório de alto padrão.

(14) Um indicativo disso é o fato de que 91\% e 95\% dos Cepacs das OUCs AE e FL, respectivamente, já foram vinculados a algum empreendimento imobiliário, restando poucos títulos em circulação que poderiam estar disponíveis para a venda no mercado de capitais. Dados obtidos dos relatórios financeiros disponibilizados pela Prefeitura Municipal de São Paulo. Disponíveis em: http://www.prefeitura.sp.gov.br/cidade/secretarias/urbanismo/sp_urbanismo/operacoes_ urbanas/index.php?p=19525. Acesso em: 1으 nov 2016.

(15) Faz parte do escopo da pesquisa à qual este artigo se vincula esclarecer essas questões no que se refere à experiência de São Paulo, o que será objeto de discussão em trabalhos futuros. A ausência dessas análises aqui é justificável, uma vez que, já que não é recorrente a negociação do título na bolsa de valores, não há análises públicas sistematizadas como há para outros tipos de título. Destaca-se, ainda, que boa parte da negociação de Cepac no mercado secundário é realizada fora do ambiente da bolsa, por meio de escrituração, intermediada pelo Banco do Brasil, sobre o que não há um registro histórico organizado, conforme informações obtidas por meio de entrevistas. 
(16) A primeira fase da operação foi realizada pelo Consórcio Saúde - Gamboa, formado pela Construtora OAS Ltda., Empresa Industrial Técnica S.A. e Odebrecht Serviços de Engenharia e Construção S.A. A segunda fase, licitada para formação de uma PPP através da modalidade de concessão administrativa, está sob a responsabilidade do consórcio Porto Novo, composto pela Construtora OAS Ltda., Construtora Norberto Odebrecht Brasil S.A. e Carioca Christiani-Nielsen Engenharia S.A. (Cardoso, 2009, p. 75).

(17) Cabe destacar que a falta de liquidez na venda dos ativos desencadeou um novo aporte do FGTS de 1,5 bilhão em 2015 (além dos 3,5 bilhões iniciais com a compra dos Cepacs). Além disso, ressalta-se que o suporte financeiro do FI-FGTS está sendo investigado, em função de suspeita de que teria sido condicionado a pagamento de propina pelas construtoras que atuam na OUC, envolvendo o então presidente da Câmara, Eduardo Cunha, e seu cunhado, Fábio Cleto, vicepresidente da Caixa Econômica Federal na época. Disponível em: http://www1.folha.uol.com. br/poder/2016/07/1790371-cunha-agia-para-favorecer-odebrecht-em-fundo-diz-delator.shtml. Acesso em: 15 jul 2016.

(18) Ressalta-se que algumas dessas empresas figuram entre os grandes financiadores eleitorais, conforme consta da reportagem "As quatro irmãs: Odebrecht, OAS, Camargo Corrêa e Andrade Gutierrez": "No Estado do Rio de Janeiro, o PMDB é de longe o partido mais beneficiado, com $\mathrm{R} \$ 6,27$ milhões, mais que a soma dos quatro seguintes: PT, PSDB, PV e DEM. Porém os repasses podem ser ainda maiores em anos não eleitorais. Em 2013, por exemplo, somente a Odebrecht repassou $\mathrm{R} \$ 11$ milhões dos $\mathrm{R} \$ 17$ milhões arrecadados pelo PMDB". Disponível em: http://www. brasildefato.com.br/node/29039. Acesso em: 15 jan 2016.

\section{Referências}

AALBERS, M. B. (2008). The financialization of home and the mortgage market crisis. Competition \& Change, v. 12, n. 2, pp.148-166.

ALVIM, A. B.; ABASCAL, B. H. e MORAES, L. G. (2011). Projeto urbano e operação urbana consorciada em São Paulo: limites, desafios e perspectivas. Cadernos Metrópole. São Paulo, v. 13, n. 25, pp. 213-233.

ASCHER, F. (2010). Os novos princípios do urbanismo. São Paulo, Romano Guerra.

BRENNER, N. (2004). New state spaces: urban governance and the rescaling of statehood. Oxford, Oxford University Press.

CAGNIN, R. F. (2012). A evolução do financiamento habitacional no Brasil entre 2005 e 2011 e o desempenho dos novos instrumentos financeiros. Boletim de Economia, v. 11, n. 1, pp. 15-32.

CARDOSO, I. C. (2013). O papel da Operação Urbana Consorciada do Porto do Rio de Janeiro na estruturação do espaço urbano: uma "máquina de crescimento urbano"? O Social em Questão Ano XVI. Rio de Janeiro, n. 29, pp. 69-100.

COMA, M. C. (2011). Del sueño olímpico al proyecto Porto Maravilha: el 'eventismo' como catalizador de la regeneración a través de grandes proyectos urbanos. Revista Brasileira de Gestão Urbana, v. 3, n. 2, pp. 211-227. 
FAINSTEIN, S. (2001). The city builders: property development in New York and London, 1980-2000. Lawrence, University Press of Kansas.

FIX, M. (2009). Uma ponte para a especulação - ou a arte da renda na montagem de uma "cidade global". Caderno CRH. Salvador, v. 22, n. 55, pp. 41-64.

(2011). Financeirização e transformações recentes no circuito imobiliário no Brasil. Tese de Doutorado. Campinas, Universidade Estadual de Campinas.

GAFFNEY, C. (2010). Mega-events and socio-spatial dynamics in Rio de Janeiro, 1919-2016. Journal of Latin American Geography, v. 9, n. 1.

GONÇALVES, R. (2012) O Governo Lula e o Nacional-Desenvolvimentismo às avessas. Revista da Sociedade Brasileira de Economia Política, n. 31, pp. 5-30

GUIRONNET, A. e HALBERT, L. (2015). Urban development projects, financial markets, and investors: a research note. Chairville, École des Ponts Paritech.

HACKWORTH, J. e SMITH, N. (2001). The changing state of gentrification. Tijdschrift voor Economische en Sociale Geografie. Hoboken, v. 22, n. 2, pp. 464-477.

HARVEY, D. (1989). From managerialism to entrepreneurialism: the transformation of urban governance in late capitalism. Geografiska annaler. Swedish, v. 71, n. 1, pp. 3-17.

HILLER, H. (2000). Mega-events, urban boosterism and growth strategies: an analysis of the objectives and legitimations of the Cape Town 2004 Olympic Bid. International Journal of Urban and Regional Research, v. 24, n. 2, pp. 439-458.

JONAS, A. E. G. e WILSON, D. (1999). The urban growth machine. Critical perspectives, two decades later. Nova York, State University of New York Press.

KAIKA, M. e RUGIERRO, L. (2016). Land financialization as a "lived" process: The transformation of Milan's Bicocca by Pirelli. European Urban and Regional Studies, v. 23, n. 1, pp. 3-22.

KLINK, J. (2014). The hollowing out of brazilian metropolitan governance as we know it: restructuring and rescaling the developmental state in metropolitan space. Antipode (Oxford. Print), v. 46.

KLINK, J. e DENALDI, R. (2014). On financialization and state spatial fixes in Brazil. A geographical and historical interpretation of the housing program My House My Life. Habitat International, n. 44, pp. 220-26.

LAW-YONE, H. (2007). Another planning theory? Rewriting the meta-narrative. Planning Theory, n. 6, pp. 315-326.

LOGAN, J. e MOLOTCH, H. (1987). Urban fortunes: the political economy of place. Los Angeles, University of California Press.

NAKANO, K. (2015). Elementos demográficos sobre a densidade urbana da produção imobiliária: São Paulo, uma cidade oca? Tese de Doutorado. Campinas, Universidade Estadual de Campinas.

NOBRE, E. C. (2009). Quem ganha e quem perde com os grandes projetos urbanos? Avaliação da Operação Urbana Consorciada Água Espraiada em São Paulo. Cadernos Ippur. Rio de Janeiro, v. 23, n. 1, pp. 203-219.

PESSOA, L. C. e BÓGUS, L. M. (2008). Operações urbanas - nova forma de incorporação imobiliária: o caso das Operações Urbanas Consorciadas Faria Lima e Água Espraiada. Cadernos Metrópole. São Paulo, n. 20, pp. 125-139. 
ROLNIK, R. (2015). Guerra dos lugares. A colonização da terra e da moradia na era das finanças. Tese de livre docência. São Paulo, Universidade de São Paulo.

ROYER, L. O. (2014). Financeirização da política habitacional: limites e perspectivas. São Paulo, Annablume.

SÁNCHEZ, F. et al. (2004). Produção de Sentido e Produção do Espaço: convergências discursivas nos grandes projetos urbanos. Revista Paranaense de Desenvolvimento. Curitiba, n. 107, pp. 39-56.

SAVINI, F. e AALBERS, M. (2015). The de-contextualisation of land use planning through financialisation: Urban redevelopment in Milan. European Urban and Regional Studies. United Kingdom, v. 23, n. 4, pp. 1-17.

SíGOLO, L. (2014). O boom imobiliário na metrópole paulistana: o avanço do mercado formal sobre a periferia e a nova cartografia da segregação socioespacial. Tese de Doutorado. São Paulo, Universidade de São Paulo.

SIQUEIRA, M. T. (2014). Entre o fundamental e o contingente: dimensões da gentrificação contemporânea nas operações urbanas em São Paulo. Cadernos Metrópole. São Paulo, v. 16, n. 32, pp. 391-415.

SMITH, N. (2002). New globalism, new urbanism: gentrification as global urban strategy. Antipode, v. 34, n. 3, pp. 429-450.

STROHER, L. (2017). Reestruturação da metrópole periférica e o impasse da reforma urbana em Curitiba. Eure, v. 43, n. 128, pp. 273-294.

SWYNGEDOUW, E.; MOULAERT, F. e RODRIGUEZ, A. (2002). Neoliberal urbanization in Europe: largescale urban development projects and the new urban policy. Antipode, n. 34, pp. 542-577.

WEBER, R. (2010). Selling city futures: the financialization of urban redevelopment policy. Economic Geography, v. 86, n. 3, pp. 251-274.

Texto recebido em 10/dez/2016

Texto aprovado em 22/abr/2017 
